\title{
Pathologic Examination
}

National Cancer Institute

\section{Source}

National Cancer Institute. Pathologic Examination. NCl Thesaurus. Code C125006.

An assessment of disease process to include cause, development, and/or structural and functional changes associated with the disease. 